\title{
Confinement and certificates: consensus, stigma and disability rights
}

\author{
Cite as: CMAJ 2020 November 30;192:E1642-3. doi: 10.1503/cmaj.201750
}

W hen examining patients showing mental distress, physicians in Ontario can fill out a "Form 1 - Application by Physician for Psychiatric Assessment." Following the Ontario Mental Health Act 1990, this form authorizes the detention of a person in a psychiatric facility for a maximum of 72 hours. ${ }^{1}$ To justify this measure, medical practitioners indicate whether they believe a patient might harm themselves in the future, harass other people or experience a clinical deterioration. For each statement, the Form 1 asks physicians to differentiate between "my own observations" and "facts communicated by others." Every day, doctors in Ontario use this peculiar formula without realizing its remarkable history.

The structure of Ontario's Form 1 dates back to 1853 , when it first appeared as the layout for certificates of insanity in Victorian England. ${ }^{3}$ With the expansion of the British empire during the second half of the nineteenth century, many countries accepted lunatic asylums as the elective choice for dealing with mental distress. To regulate admissions into such establishments, English lunacy certificates became the standard in numerous jurisdictions around the globe, including India, Tasmania, Sierra Leone, the Strait Settlements and, of course, Ontario. ${ }^{4}$ English-speaking physicians working in diverse contexts would perform an examination and fill out a prescribed template that distinguished between "facts of insanity personally observed" and "facts communicated by others."

Despite the global success of this formula, the diffusion of English lunacy certificates was not a passive process in which the "periphery" simply followed the way of the "metropole." As historians of empires have pointed out, colonial exchanges always implied accommodation and hybridization. ${ }^{5}$ In the case of mental health law, most jurisdictions under direct or indirect British rule adopted certification provisions inspired by, although never identical to, the ones operating in London. While maintaining the basic framework, each jurisdiction modified the requirements for certification according to local needs and customs.

Ontario was a case in point of this hybridization process. An 1873 provincial statute introduced the "Form K Certificate of Medical Practitioner in Ordinary Cases," which mandated patients to be personally examined by three doctors, not two, as originally prescribed in England (Figure 1). Besides replicating the distinction between personal and communicated facts, the Form $\mathrm{K}$ was valid only if signed by two witnesses - another addition to the English standard. This provision produced a peculiar examination setting that could involve as many as nine people three physicians and six witnesses - in the committal of a single patient.

But how did the certification process function in practice? From the records of the Toronto Lunatic Asylum we can get a

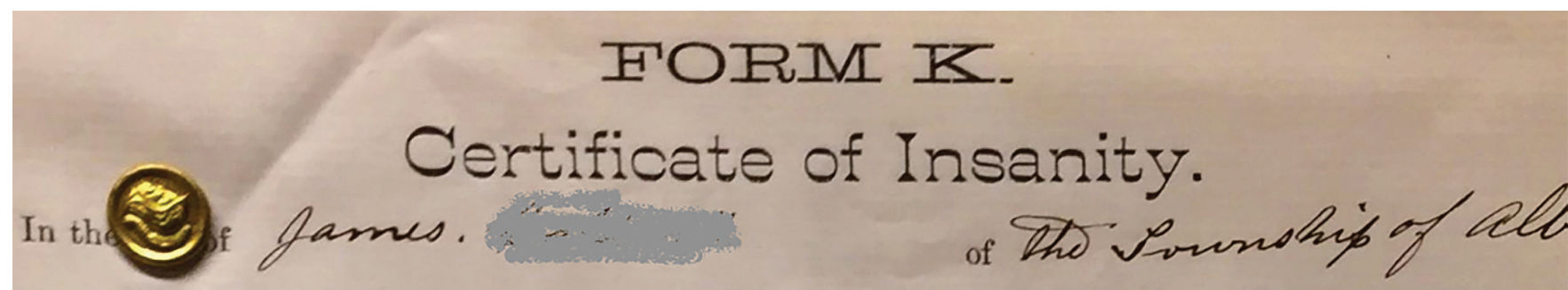

as provided under 36th Victoria, Cap. 31, Section 31, Statutes of Ontario :-

3I. The fifth, sixth, seventh, twenty-first and twenty-fourth sections of the Act respecting Asylums for the insane, passed in the thirty-fourth year of the reign of Her present Majesty, and chaptered eighteen, are hereby repealed, and the following sections are substituted in lieu of the said fifth, sixth, seventh and twenty-fourth sections respectively.

"(5.) No person shall be admitted into any of the said asylums as a lunatic (except

without the certificates (Form $\mathrm{K}$ ) of three into any of the said asylums as a lunatic (except upon an order of the Lieutenant-Governor) without the certificates (Form K.) of three medical practitioners, each attested by the signatures of two subscribing witnesses, and tearing date within three months of the time of such admission."

ofrom (6.) Each such certificate shall state that the medical practitioner signing the same personally examined the patient, separately ofrom any other medical practitioner, and that after due enquiry into all necessary facts relating to the case of such patient, found him to She insane, and the medical practitioner so certifying shall also, in such certificate specify the facts upon which he has formed his opinion Eated to him by others" such certificate relates is insane, and he shall therein distinguish facts observed by himself from facts communi-

Figure 1: An original copy of the "Form K Certificate of Insanity" employed in Ontario from 1873 to 1882. Archives of Ontario (AO), Queen Street Mental Health Series, RG 10-268. Certificate of insanity [name redacted], Queens Street Mental Health Centre admission, Archives of Ontario 
glimpse of how practitioners in Ontario engaged with their role as certifiers. Let us consider the case of Matilda R., a 27-year-old from Lincoln, described as a "farmer's wife" with 5 children. ${ }^{6}$ Her husband, Albert, recognized the first signs of her distress and contacted a local physician named Dr. Haney, who examined Matilda on July 31, 1877. In his Form K, Dr. Haney noted that Matilda "talks about everything," imagines that "her Dr. is coming from England to give her cash 1000 \$," and that "she runs constantly." In the "facts indicated by others" section, Dr. Haney wrote, "[H]er husband states that she everyday endeavors to run away, it is impossible for him to take care of her." This profile of "Matilda the runner" was confirmed by the other two certifying physicians. One day after Dr. Haney's examination, Dr. Aluray personally observed that "on questioning her, I found her mind continually wandering somewhat it was impossible to carry on any intelligent connection, and her whole general appearance indicates insanity." Dr. Aluray too, reported the opinion of Matilda's husband: "I was informed by her husband that she is constantly wandering from time and she imagines she would like to be a lumen of some other professional [sic]." The third certifying physician, Dr. Russell, offered a similar depiction. He wrote that Matilda showed "a rambling, disjointed, incoherent talk utterly devoid of sense. A vacant insane expression of countenance, imagines all sorts of ridiculous things, can't reason or speak a sensible word about anything." Once again, Dr. Russell reported that "her husband informs me that he can't keep her at home; rambles about among the neighbors, also that her mother committed suicide through insanity." With the paperwork completed, Matilda entered the Toronto asylum on Aug. 2, 1877, as a paying patient (for a history of the Toronto asylum, see G. Reaume, Remembrance of patients past: patient life at the Toronto Hospital for the Insane, 1870-1940). ${ }^{7}$

Involuntary confinement in the nineteenth century relied on a clinical judgment and facts communicated by others, similar to today's Form 1. The guiding principle behind this formula was that of consensus. For an effective certification, it was important that everybody participating in the examination could "see" the same event. Gender and class certainly played a role in the case of Matilda, and it was important that all actors provided similar facts of derangement. The idea of committal upon consensus was not related to some therapeutic recommendation. Consensus was a legal necessity. Certificates of insanity like contemporary forms - were legal documents in all respects. On one hand, they authorized physicians to charge a fee for their service. On the other, relatives and friends could appeal incorrect certificates in a court of law. As Victorians knew very well, signing an incorrect certificate could put a physician's reputation and career at risk. ${ }^{8}$ Thus, not only did certification have to look truthful, it also had to be a legally sound process for practitioners and relatives.

Over the years, the number of doctors required to involuntarily confine a patient was reduced from three to one, yet the Victorian formula survived for more than 150 years in Ontario. Perhaps one of the most important consequences of the dissemination of lunacy certificates around the world has been the stigmatization of individuals because of their documented psychiatric past. ${ }^{9}$ As a legal requirement, certificates of insanity transformed family concerns into medical, social and political issues, creating a record that was difficult to erase from bureaucracy and social memory. ${ }^{10}$ The immediate purpose was confinement in an asylum, as in the case of Matilda. Yet, by the turn of the twentieth century, the "certified insane" had become a broad category that limited the rights of people with disabilities. A certification record could restrict life-changing decisions, such as marriage, acquisition of property and emigration. As the eugenic movement gained momentum, moreover, a certificate of insanity extended the stigma to relatives and unborn children. Following the ideal of preventing the reproduction of the "unfit," certification was the starting point for eugenic speculations about racial degeneration, permanent confinement and, in some cases, sterilization. ${ }^{10}$

As a simple piece of paper, the Form 1 thus conceals a dense chronicle ranging from England to Canada, from consensus to stigma. During the last four decades, disability rights movements have advocated for a fundamental shift in the way society looks at people with disabilities, from "objects of welfare" to active citizens. ${ }^{11}$ The UN Conven- tion on the Rights of Persons with Disabilities (2006), with its emphasis on "nondiscrimination," set the conditions for denouncing stigmatizing attitudes and behaviours. The Form 1 brings us back to the origins of a documentary basis for discrimination. Physicians do not sign this document lightheartedly. They are well aware that detention in a psychiatric facility will have serious effects on a person's life. Considering the long history of this form, however, doctors and policy-makers in Ontario are reminded of the insidious legacy of stigmatizing practices in contemporary mental health documents.

\section{Filippo Maria Sposini MSc}

Osgoode Society, Institute for the History and Philosophy of Science \& Technology, University of Toronto, Toronto, Ont.

\section{References}

1. Ontario Mental Health Act, RSO 1990, c M-7. Last amended SO 2015, c 36.

2. Schneider RD. The annotated Ontario mental health statutes. 4th ed. Toronto: Irwin Law; 2007.

3. Wright $D$. The certification of insanity in nineteenthcentury England and Wales. Hist Psychiatry 1998;9:267-90.

4. Sposini FM. Just the basic facts: The certification of insanity in the era of the Form K. J Hist Med Allied Sci 2020;75:171-92.

5. Dorsett S, McLaren J, editors. Legal histories of the British Empire: laws, engagements and legacies. New York: Routledge; 2014.

6. RG 10-268, B296104, Admission No. 4891. Toronto: Archives of Ontario.

7. Reaume G. Remembrance of patients past: patient life at the Toronto Hospital for the Insane, 18701940. Toronto: Oxford University Press; 1997.

8. McCandless P. Liberty and lunacy: the Victorians and wrongful confinement. J Soc Hist 1978;11:366-86.

9. Marcussen K, Gallagher M, Ritter C. Mental illness as a stigmatized identity. Soc Ment Health 2019;9: 211-27.

10. Porter TM. Genetics in the madhouse: the unknown history of human heredity. Princeton (NJ): Princeton University Press; 2018.

11. Bartlett P. The United Nations Convention on the Rights of Persons with Disabilities and the future of mental health law. Psychiatry 2009;8:496-8.

Funding: This work was supported by The Osgoode Society for Canadian Legal History, the Friends of the Centre for Addiction and Mental Health (CAMH) Archives, and the Government of Ontario.

Acknowledgments: Many thanks to Marga Vicedo, Mark Solovey, Jim Phillips and Geoffrey Reaume for their comments and support along the way. The author is grateful to Dorian Deshauer and his unparalleled editorial skills. Thanks to the anonymous reviewers who provided thoughtful comments and suggestions.

Competing interests: None declared. 